\title{
Analysis on the Influencing Factors of Driving Behaviours Based on Theory of Planned Behaviour
}

\author{
Lisheng Jin $\left(\mathbb{D},{ }^{1}\right.$ Baicang Guo $\mathbb{D}^{1},{ }^{1,2}$ Yuying Jiang $\mathbb{D}^{3},{ }^{3}$ and Qiang Hua $\mathbb{i D}^{2}$ \\ ${ }^{1}$ School of Vehicle and Energy, Yanshan University, Qinhuangdao 066004, China \\ ${ }^{2}$ Transportation College, Jilin University, Changchun 130022, China \\ ${ }^{3}$ Department of Ophthalmology, China-Japan Union Hospital, Jilin University, Changchun 130022, China
}

Correspondence should be addressed to Baicang Guo; guobaicang@126.com

Received 9 October 2020; Revised 6 December 2020; Accepted 10 December 2020; Published 29 January 2021

Academic Editor: Hui Yao

Copyright ( $\odot 2021$ Lisheng Jin et al. This is an open access article distributed under the Creative Commons Attribution License, which permits unrestricted use, distribution, and reproduction in any medium, provided the original work is properly cited.

Driving behaviour is a complex and multidisciplinary research domain, and bad driving behaviours that threaten the safety of road users should be refrained. In order to better educate, manage, and restrain driver's behaviours, from the perspective of human factors and psychology, the present study deconstructed driving behaviours based on theory of planned behaviour (TPB) into five categories: mistakes (Mis), lapses and slips (LaS), violations (Vio), driving experience (Exp), and safety attitude and awareness (SAA). According to today's practical traffic rules and conditions in China, a driving behaviour questionnaire was built as an analysing tool and the survey data were collected in accordance with the demographic of Chinese drivers. Furthermore, a driving behaviour analysis model contains the aforementioned categories was established by using the structural equation model (SEM). Through the path analysis results among latent variables and manifested variables, it was found that Exp has an impact on Vio and LaS, and better SAA can inhibit Vio and Mis. In conclusion, the prime aim of improving road traffic safety is to reduce Vio by means of educating and improving the drivers' Exp and SAA. Moreover, drivers' LaS and Mis are transition processes which should be corrected timely and prevented from continuing to evolve into Vio.

\section{Introduction}

The economic development of contemporary China has increased the number of private vehicles. As shown in Figure 1, the growth trend of drivers is fierce; by December 2019, there are 435 million motor vehicle drivers and 397 million car drivers in China. The problems caused by the rapid population growth of drivers are the increasing difficulty of traffic management and incidence of traffic accidents. Driving safety has always been a common concern for researchers and the public. Statistics have shown that approximately 1.25 million people worldwide and approximately 100,000 people in China die due to road traffic accidents each year [1-3]. The research results on the causes of road traffic accidents showed that people are the key factors leading to traffic accidents, and drivers, as the operators of vehicles, are one of the most crucial causes of road traffic accidents. Consequently, before the era of fully automatic driving, it is necessary to analyse the driver's influencing factors and take differential corrective measures for bad behaviours. Moreover, it also provides help for the study of humanoid behaviours of autonomous driving.

In the field of driving experience and driving behaviours, on-road experience plays an important role to strengthen hazard mitigation skills [4-6] and also helps to alleviate the tendency of distracted driving behaviour [7]. Experienced drivers show reduced crash risks in comparison to novice drivers [8], which means driving experience helps to allocate attention resources effectively to identify potential hazards [9]. Lacking maturity and driving experience increases the risk of traffic accidents for novice drivers [10]. Pnina et al. [11] found that although there are a lot of driving practices during the learning period, the probability of making mistakes in early license holding period is still high. Lack of driving experience is related to the driver's insufficient ability to monitor potential road hazards, which can lead to rear end, fatigue driving, drunk driving, or other behaviours 


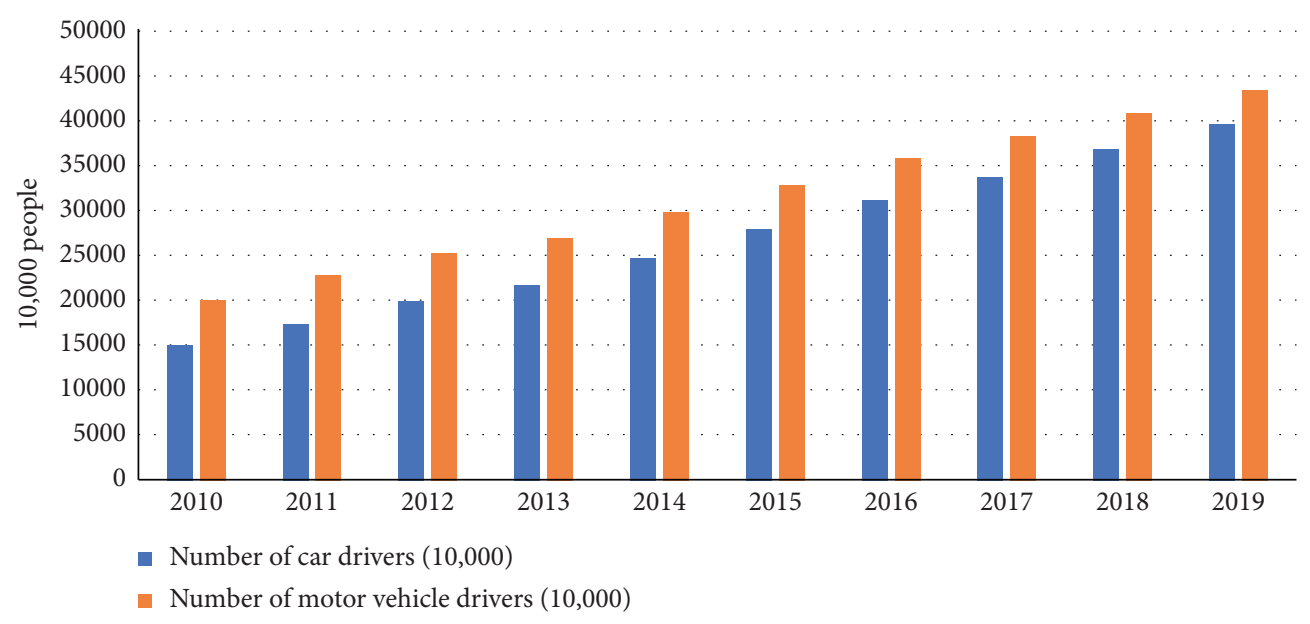

FIgURE 1: Driver growth trend in China in the past 10 years (data source: National Bureau of Statistics, 2019, China).

[12]. When dealing with incidents on road, experienced drivers exhibited more proactive actions than novices [13]; moreover, experienced drivers are better than novices in situational perception [14]. In conclusion, lack of driving experience is a safety threat to drivers, passengers, and other road users. Driving experience has a strong correlation with driver's psychology (self-confidence, attitude, and awareness), emergency response ability, peripheral monitoring ability, etc.

In the domain of psychology and driving behaviours and in the aspect of driver's psychology on driving behaviour, many research studies have shown that Theory of Planned Behaviour (TPB) can be used to explain driving behaviours (e.g., Przepiorka et al. [15]; Waddell and Wiener [16]; and Walsh et al. [17]). One of the basic TPB hypothetical models is to use intention to predict behaviours, whilst intentions result from an individual's attitude towards the behaviour, subjective norms, and perceived behavioural control (PBC) over the behaviour. Attitude is the positive or negative evaluation of the behaviour [18]. Subjective norms refer to the constraints that individuals feel about whether to execute a particular behaviour. PBC is the perceived level of control that one has over engaging in or refraining from engaging in this behaviour [19]. Furthermore, factors such as emotional driving and sensation seeking can lead to dangerous driving behaviours. Novice drivers have a high risk of distraction when travelling with young passengers, which Siebe [20] believes is due to a lack of confidence in vehicle control.

With respect to human factor research, driving behaviour questionnaire (DBQ) is one of the most widely used tools to measure self-reported driving style and investigate the relationship between driving behaviour and accident participation [21]. Based on the theoretical classification of abnormal behaviours, $\mathrm{Qu}$ et al. [22] divided driving behaviours into three types: slips and lapses, mistakes, and deliberate violations $[22,23]$. In the follow-up research on DBQ, scholars confirmed the rationality of the three-factor structure of DBQ in their own research studies and proved that DBQ is relatively reliable over time [24-26]. Rimmö et al. [27] utilized three-factor structure (aggressive violations, ordinary violations, and errors) compare driving behaviours across six countries, and they found that the importance of driver characteristics and behaviours in predicting traffic accidents varies from country to country.

Therefore, in practical application research, scholars in different countries will consider the local traffic conditions, cultural habits, and other actual conditions and make corresponding deletion, supplement, and adjustment of DBQ according to their research purposes. Bener et al. [21] and Mesken et al. [28], respectively, investigated Qatar and the United Arab Emirates with their own DBQ and, respectively, analysed the relationship among several driving behaviours and traffic accidents by the Driver Positive Behaviour Scale (DPBS) and Driver Aggression Indicators Scale (DAIS). Cordazzo et al. [29] included more driving behaviour samples based on the previous version of DBQ and conducted research on driving behaviours such as targeting inattention, distraction, and aggressive driving. Lajunen et al. [30] studied the applicability of Manchester DBQ in three countries: Finland, the United Kingdom, and the Netherlands. Their conclusion shows that although the classification methods of the DBQ factor structure in these three countries are not exactly the same, the original DBQ structure is still applicable to these three countries. In China, after resulting the questionnaire on some Chinese people in Beijing and Chengde, Jing Shi et al. [31] divided the violations into emotional violations, risky violations, and self-willed violations, and the errors included inexperience errors and distraction errors.

According to the abovementioned literature studies, it can be found that scholars have extensive and lasting interest in studying driving behaviour (types, causes, and impact on traffic safety) by exploring the psychology and driving experience of drivers. This paper studies from the following aspects:

(1) From the illation of TPB, for laying a foundation for questionnaire analysis, we deduce the influencing mechanism of driving behaviours and deconstruct the influencing factors of driving behaviours into latent variables and manifest variables. 
(2) By referencing and adapting proper items from Manchester Driver Behaviour Questionnaire [22], Dula Dangerous Driving Index [32], and Chinese Driving Questionnaire [33], additionally we put forward some items with Chinese characteristics. After that, a Chinese driving behaviour questionnaire with good reliability and validity is proposed.

(3) A driving behaviour analysis model based on SEM is established by matching items as manifest variables to latent variables. After model calculation, the path analysis results are utilized to show the main factors that influence the driving behaviours.

\section{Materials and Methods}

\subsection{Driving Behaviour Questionnaire}

2.1.1. Driving Behaviours and Its Influencing Factors. The present study mainly focuses on Chinese drivers' psychology and driving experience and explores the mechanism of their influence on driving behaviours. At first, a self-reported questionnaire was designed and produced as the observation variable of the subsequent SEM model. The contents of the questionnaire are mainly divided into three types of driving behaviour (lapses and slips, mistakes, and violations) and three types of influencing factors (driving experience, rules and regulations, and psychology).

(1) Driving behaviours

The present study chose 3 typical driving behaviours (violations, lapse and slips, and mistakes) which are quoted directly or revised from classical previous studies [22, 24, 32]; meanwhile, the revised ones are modified in line with the actual traffic situation in China. For example, (1) the radical driving style of motorcycles for delivery who are usually cut-in recklessly or stop suddenly is easy to cause road chaos and give challenges to drivers' driving skills, temper, mental states, etc. (2) Although the traffic laws and penalties have been strengthened in the past few years, the Yield Here to Pedestrians in China is just in its infancy, the phenomenon of the Chinese crossing the road (gathering several people to cross the road and ignore the traffic lights) usually forces drivers to give the way even on green lights, and the drivers' emotion and mood may be changed in a negative or aggressive direction. (3) Due to different transportation facilities in different countries, some items, such as pelican crossing light (variable 37 in DBQ [22]), are inapplicable in China. In addition, inspired by the mechanism of driving behaviour research studies about Chinese drivers [34-38]), the other items were proposed based on authors' empirical views of actual road conditions, driving habits, traffic rules and regulations, etc. in China.

(a) Slips, lapses, and mistakes

Errors (slips, lapses, and mistakes) may be accounted for by reference to the information-processing characteristics of the individual. Reason et al. [22] defined that the failure of planned actions to achieve their intended consequences can involve two psychologically distinct kinds of "straying": the unwitting deviation of action from intention (slips and lapses) and the departure of planned actions from some satisfactory paths towards a desired goal (mistakes).

Therefore, the difference between error and slips or lapses is as follows: slips and lapses are undesirable results of involuntary actions and behaviours without thinking and decision-making, while error is caused by conscious deviation from rules or safety practices, mainly from the attitude and/or psychology of drivers [38, 39]. Norman [40] expressed it as follows: "if the intention is not appropriate, this is a mistake. If the action is not what was intended, this is a slip."

Unintentional violations often result from the driver's unintentional decisions, and the causes of unintentional violations are mostly misjudgement or error [41, 42]. For this reason, in this study, some unintentional violations are classified as errors or lapses and slips.

(b) Violations

Violations require explanation in terms of social and motivational factors [22]. This kind of behaviour of drivers will cause safety threats to other users on the road and have a negative impact on traffic safety. The reasons for the generation of violations are mainly divided into sense seeking and motion, egoism et al. [43]. Considering the influence of driver's mood, driving style, and characteristics on driving safety, the present study classifies violation driving behaviours into three categories: aggressive driving behaviour, emotional driving behaviour, and egoism driving behaviour. It is worth mentioning that the common unique road conditions in China are taken into consideration when formulating items, for example, (1) groups of takeout two-wheelers do not drive in a standard way, which is easy to cause road chaos or irritate drivers. (2) The phenomenon of the Chinese crossing scene (gathering enough people to cross the road and ignore the traffic lights) puts forward higher requirements for driver's courtesy to pedestrians and emotional adjustment.

(2) Influencing factors

(a) Driving experience

Since it is a vague and abstract concept, it is necessary to make a definition of the driving experience: rich driving experience means that the driver can play a positive role in maintaining and promoting traffic safety, which shows that they have good driving skills (driving stably, efficiently, and safely) and active solutions to road problems, as well as better emotional management and self-control ability. This paper proposes the hypothesis that experience has 
variable influence on driving behaviours. Variables used to observe driving experience include emergency handling, vehicle condition control and monitoring, etc.

(b) Rules and regulations

Rules and regulations can affect driving behaviours from two perspectives: the first is that there are external constraints on drivers. Studies have found that human behaviour is not entirely voluntary, but under control $[1,44]$. This paper holds that road rules and regulations, to some extent, are the factors to regulate and control the behaviour of drivers, and all drivers are supposed to be within the scope of this control. The driver's compliance with the rules and regulations limits some of his/her driving behaviours.

On the other hand, the existence of rules and regulations makes drivers have subjective internal locus of control [36, 45, 46]. People with high internal locus of control may have a more positive attitude towards maintaining traffic safety.

(c) Psychology

Attitude is a behavioural belief which has been shown approximately 50 percent of variance in intentions and approximately 30 percent in overall behaviour $[1,2]$. Studies have tested the relevancy of attitude as a significant predictor and found it to be the significant [47-49]. Therefore, the driver's attitude plays a certain role in promoting or guiding the behaviour and the quality of the behaviour. On the other side, self-confidence and psychology are the important factors that influence drivers' intention and intervene their behaviour $[45,50,51]$. Moreover, as a daily activity, driving behaviour is influenced by various stressors [12, 52, 53], for example, when there are family or friends in the car, if the driver feels nervous, it may increase the probability of errors. The abovementioned points are in line with TPB: behaviour attitude, subjective norm, and perceptual behaviour control are the three main variables that determine behaviour intention. Thus, the psychology of this paper includes self-confidence, attitude, and awareness.

2.1.2. Questionnaire Contents. The questionnaire is mainly divided into two parts, the first part is the demographic characteristics of the subjects and the second part is the main body of the questionnaire:

(1) Demographic characteristics of the subjects: the proportion of gender and age of the investigated population should conform to the distribution of demographic characteristics of Chinese drivers, so that the sample can accurately and reasonably reflect the overall representativeness. The questionnaire needs to collect the information of the subjects including gender, age, and years of license.
(2) Main survey: the second part of the questionnaire is all of the rest items, the original is Chinese, and the English version is translated by two doctoral students majoring in transportation engineering. Details are provided in Supplementary Materials.

\subsection{Measures}

2.2.1. Procedure. All participants were informed that their information would be strictly confidential and would be used only for research. The questionnaires took approximately 6 minutes to complete. Participants received $¥ 8$ compensation when they finished the questionnaire.

The questionnaire was designed using 5-point Likert scales [31]. Subjects were asked to rate how often they committed the behaviours described in the items. The options ranged from 0 to 5 as follows: 0 , never; 1 , hardly ever; 2 , occasionally; 3 , often; 4 , frequently; and 5 , nearly all the time.

2.2.2. Subjects. In the opinions of Rigdon et al. [54] and Tabachnick et al. [54], a sample larger than 200 can be considered as a medium-sized sample; to pursue stable SEM analysis results, it is better to have a sample larger than 200 . If the number of samples is less than 150, the model estimation will be unstable, and the statistical testing strength of the model will be very low [56-59].

Referencing to the demographic characteristics of Chinese drivers, questionnaires are randomly distributed throughout China with conditions (controlling gender, age, etc.) through an online platform. The subjects under investigation have a Chinese-approved driving license. The questionnaires were successfully issued and recovered twice. After sorting out and eliminating invalid questionnaires, the effective questionnaires actually recovered for the first and second times were 262 and 528, respectively. The demographic data of the subjects are shown in Table 1.

\subsection{Data Analysis}

2.3.1. Reliability Test. In the research domain of human factors, many things cannot be measured directly and the questionnaires are often chosen as solutions by researchers. However, whether these items can achieve the purpose of research requires further analysis through statistical measure. Consequently, Cronbach's $\alpha$ is often used to measure the level of observational consistency of different items in the same dimension (especially when using the Likert scale [60]). The larger the value of $\alpha$, the stronger the internal consistency. The consistency level corresponding to each level of Cronbach's $\alpha$ is shown in Table 2 .

After testing the reliability of the whole and part of the first questionnaire, we found that the overall reliability is excellent (68 items, Cronbach's $\alpha=0.95$ ), but three parts (emergency response, rules and regulations, and psychology) are poor/unacceptable Table (see 3 ), which means the internal consistency is not ideal and the structure is supposed to be modified. 
TABLE 1: Demographic characteristics of survey subjects.

\begin{tabular}{|c|c|c|c|c|c|c|}
\hline \multirow{4}{*}{$\begin{array}{l}\text { Demographic characteristics } \\
\text { Gender }\end{array}$} & \multicolumn{2}{|c|}{ First survey } & \multicolumn{2}{|c|}{ Second survey } & \multirow{2}{*}{\multicolumn{2}{|c|}{$\begin{array}{l}\text { Percentage of total } \\
\text { Chinese driver } \\
\text { population in } 2019\end{array}$}} \\
\hline & \multirow{3}{*}{$\begin{array}{c}\text { Quantity } \\
\text { Male } \\
\text { Female }\end{array}$} & \multirow{3}{*}{$\begin{array}{c}\text { Percentage } \\
170 \\
92\end{array}$} & \multirow{3}{*}{$\begin{array}{c}\text { Quantity } \\
65 \% \\
35 \%\end{array}$} & \multirow{3}{*}{$\begin{array}{c}\text { Percentage } \\
348 \\
180 \\
\end{array}$} & & \\
\hline & & & & & $66 \%$ & $70 \% *$ \\
\hline & & & & & $34 \%$ & $30 \%{ }^{*}$ \\
\hline \multirow{4}{*}{ Age } & $18 \sim 25$ & 101 & $39 \%$ & 148 & $28 \%$ & - \\
\hline & $26 \sim 35$ & 83 & $32 \%$ & 201 & $38 \%$ & $34.12 \% *$ \\
\hline & $36 \sim 50$ & 73 & $28 \%$ & 174 & $33 \%$ & $38.88 \% *$ \\
\hline & $>60$ & 5 & $2 \%$ & 5 & $1 \%$ & $2.9 \%^{*}$ \\
\hline \multirow{4}{*}{ Years of license } & $0 \sim 1$ & 30 & $11 \%$ & 48 & $9 \%$ & $7.94 \%^{* *}$ \\
\hline & $1 \sim 3$ & 74 & $28 \%$ & 211 & $40 \%$ & - \\
\hline & $3 \sim 9$ & 72 & $27 \%$ & 174 & $33 \%$ & - \\
\hline & $>10$ & 37 & $14 \%$ & 95 & $18 \%$ & - \\
\hline Sample size & & 262 & & 528 & & \\
\hline
\end{tabular}

TABLE 2: Internal consistency level corresponding to Cronbach's $\alpha$.

\begin{tabular}{lc}
\hline Cronbach's $\alpha$ & Internal consistency \\
\hline $0.9 \leq \alpha$ & Excellent \\
$0.8 \leq \alpha<0.9$ & Good \\
$0.7 \leq \alpha<0.8$ & Acceptable \\
$0.6 \leq \alpha<0.7$ & Questionable \\
$0.5 \leq \alpha<0.6$ & Poor \\
$\alpha<0.5$ & Unacceptable \\
\hline
\end{tabular}

Considering the number of observation variables contained in each latent variable is not more than 15 , which is beneficial to improve the goodness-of-fit of SEM, the total number of items has reached 59 after several exploratory adjustments and deletion. According to the actual content of the items, emergency response, rules and regulations, and psychology are separated, reorganized, and replaced by safety awareness and attitude.

Finally, the deconstruction way of latent variable which meets the reliability standard is obtained. Cronbach's $\alpha$ of all latent variables is greater than 0.7 (see Table 4), and Cronbach's $\alpha$ of the whole items is 0.946 . It shows that the overall reliability of the current questionnaire is good and the data are reliable [61].

2.3.2. Validity Test. In this paper, the KMO and Bartlett spherical test was conducted on the sample data and the maximum variance method was used to rotate the factors. Previous literature studies hold when the value is KMO test coefficient larger than 0.8 , and the results could have better worth and practicability. From Table 5, the KMO statistic result indicates that the data structure of this study is good and performs internal correlation. The statistical significance probability of Bartlett's spherical test $(P<0.001)$ indicates that the validity of factor analysis data is good.
TABLE 3: Reliability test of initial latent variables.

\begin{tabular}{|c|c|c|c|c|}
\hline $\begin{array}{l}\text { Latent } \\
\text { variables }\end{array}$ & Items & Quantity & $\begin{array}{c}\text { Cronbach's } \\
\alpha\end{array}$ & Reliability \\
\hline $\begin{array}{l}\text { Lapse and } \\
\text { slips }\end{array}$ & $\mathrm{L} 1 \sim \mathrm{L} 18$ & 18 & 0.886 & Good \\
\hline Mistakes & M1 M9 & 9 & 0.859 & Good \\
\hline Violations & $\mathrm{D} 1 \sim \mathrm{D} 18$ & 18 & 0.881 & Good \\
\hline Experience & $\mathrm{H} 1 \sim \mathrm{H} 11$ & 11 & 0.885 & Good \\
\hline $\begin{array}{l}\text { Emergency } \\
\text { response }\end{array}$ & $\mathrm{E} 1 \sim \mathrm{E} 3$ & 3 & 0.602 & Poor \\
\hline $\begin{array}{l}\text { Rules and } \\
\text { regulations }\end{array}$ & $\mathrm{R} 1 \sim \mathrm{R} 4$ & 4 & 0.556 & Unacceptable \\
\hline Psychology & $\mathrm{P} 1 \sim \mathrm{P} 5$ & 5 & 0.541 & Unacceptable \\
\hline
\end{tabular}

\subsection{Driving Behaviour Analysis Model Based on SEM}

2.4.1. Hypothetical Structural Model. The proposed primary hypothetical model is shown in Figure 2. According to the relevant criteria of the TPB, the comprehensive analysis of the factors affecting the driver's behaviour is carried out. Furthermore, each driving behaviour module and influencing factor module are proposed, and the logical relationship of each module is expressed in the form of paths:

(1) According to TPB, learning from the outside world (knowledge, ideas, etc.) will indirectly/directly affect behaviour attitude, subjective norms, and perceptual behaviour control and ultimately affect intention and behaviour. Therefore, driving experience is an important factor influencing driver's behaviour. In the hypothesis model, the Exp includes emergency response, bad driving habits, peripheral monitoring (front, rear, left, and right), etc.

(2) In TPB, behaviour attitude, subjective norm, and perceptual behaviour control are the three main variables that determine behaviour intention. Therefore, SAA in this model includes observation variables such as safety awareness, subjective attitude, and traffic norm awareness. 
TABLE 4: Test results of adjusted latent variable reliability.

\begin{tabular}{|c|c|c|c|c|c|}
\hline Latent variables & Abbr. & Items & Quantity & Cronbach's $\alpha$ & Reliability \\
\hline Lapse and slips & $\mathrm{LaS}$ & $\mathrm{L} 8 \sim \mathrm{L} 18, \mathrm{M} 2$ & 12 & 0.855 & Good \\
\hline Mistakes & Mis & M1, M3 M9, D3, D9, R2, L6 & 12 & 0.868 & Good \\
\hline Violations & Vio & $\mathrm{D} 1, \mathrm{D} 4, \mathrm{D} 5, \mathrm{D} 7, \mathrm{D} 8, \mathrm{D} 11 \sim \mathrm{D} 18, \mathrm{R} 1$ & 14 & 0.921 & Excellent \\
\hline Experience & Exp & $\mathrm{H} 1, \mathrm{H} 2, \mathrm{H} 7 \sim \mathrm{H} 11, \mathrm{E} 1 \sim \mathrm{E} 3$ & 10 & 0.887 & Good \\
\hline Safety attitudes and awareness & SAA & $\mathrm{P} 1 \sim \mathrm{P} 5, \mathrm{D} 2, \mathrm{D} 10, \mathrm{H} 4, \mathrm{H} 5, \mathrm{R} 3, \mathrm{~L} 3$ & 11 & 0.728 & Acceptable \\
\hline
\end{tabular}

TABLE 5: KMO and Bartlett's test.

\begin{tabular}{|c|c|c|}
\hline $\begin{array}{r}\text { Kaiser-Meyer-Olkin } \mathrm{m} \\
\text { adequ }\end{array}$ & ure of sampling & 0.912 \\
\hline \multirow{3}{*}{ Bartlett's test of sphericity } & Approx. chi-square & 9310.063 \\
\hline & df & 1711 \\
\hline & Sig. & 0.000 \\
\hline
\end{tabular}

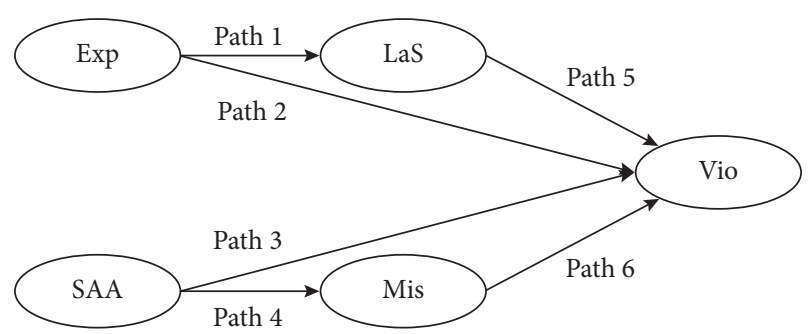

FIGURE 2: A hypothesis conceptual model of driving behaviours.

(3) Although Mis and LaS are usually unintentional violations, they may still threaten the safety of pedestrians and other road users; thus, they are used as intermediary effect in the structural model.

(4) According to Ajzen et al. [1], involuntary fully controlled behaviour is not only affected by the behaviour intention but also subject to the actual control conditions such as the subject's personal capabilities and experience. In the case of sufficient actual control conditions, behavioural intention directly determines the behaviour [62]. In the hypothesis model, SAA is the "behavioural intention," which includes driver's psychology, attitude, awareness, etc. Driver's driving experience is the constraint condition, and SAA and Exp are independent and mutually restricted to each other. Therefore, the Path 1 to Path 4 is proposed.

(5) Mis is mainly determined by the driver's awareness or psychology and is not directly related to the driving experience. Furthermore, LaS is not the result of the decision made by the driver, so it is not related to SAA.

2.4.2. SEM Test. SEM is a validated analysis model in the field of advanced statistics. It is a statistical method for analysing the relationship between variables based on the covariance matrix. It contains two secondary models: structural model and measurement model [61]. The structural model reflects the relationship between latent variables; the measurement model describes how latent variables are measured or conceptualized by the corresponding manifest indicators. Due to SEM can handle multiple manifest indicators and latent variables at the same time, it is often used to analyse concepts that are difficult to measure directly in social sciences and natural sciences.

This paper proposes manifest indicators for driving experience, psychology, etc., uses the SEM to analyse the influencing mechanism of various factors on driving behaviours, and then obtains the direct and indirect effects between each variable. The specific method is as follows: using data from the second batch of questionnaires (528 samples), the initial structural equation analysis model for driving behaviour research was constructed in AMOS 22.0. The maximum likelihood estimation method is used to estimate the parameters in the model, and the results are shown in Figure 3.

The companion probability $\mathrm{P}$ of critical ratio (C.R.) value was used to test the significance of the model's path coefficients. The path coefficients and its significance of the hypothetical model are listed in Table 6 . The chi-square value of the initial model fit is $9738.043(\mathrm{P}<0.001)$, and degree of freedom is 1646. Comparing with the recommended value in Table 7, the commonly used fitting index values, CFI and IFI, meet the requirements. However, RMSEA, $\chi^{2} / \mathrm{DF}$, GFI, AGFI, NFI, and TLI do not meet the standard, and further structural model adjustment is needed to improve the goodness-of-fit.

According to the calculation results of the significant path coefficients in Table 8 , the estimated normalized path coefficients of $\mathrm{H} 7, \mathrm{H} 11, \mathrm{P} 1$, and $\mathrm{P} 4$ are not significant. $\mathrm{H} 7$ and $\mathrm{H} 11$ were originally classified in the experience category because they examined the driver's ability to prevent risks; after analysing the items' content, these two items can try to be classified in SAA. Moreover, P1 and P4 were initially classified in the SAA because of their relationship with the driver's mental state and thoughts; from a practical point of view, the degree of driving experience will have a decisive effect on these two items. Therefore, $\mathrm{P} 1$ and $\mathrm{P} 4$ are recategorized into Exp. In addition, R3 more reflects the driver's psychological state, so it is classified in SAA.

\section{Results}

3.1. Driving Behaviour Analysis Model. Based on the above analysis and adjustment scheme, the revised structural equation model is obtained as shown in Figure 4. All the estimated values of path coefficient in the revised model are significant at the level of 0.01 , indicating that the model has good significance, the model is credible at $95 \%$ confidence, and the model modification meets the standard. 


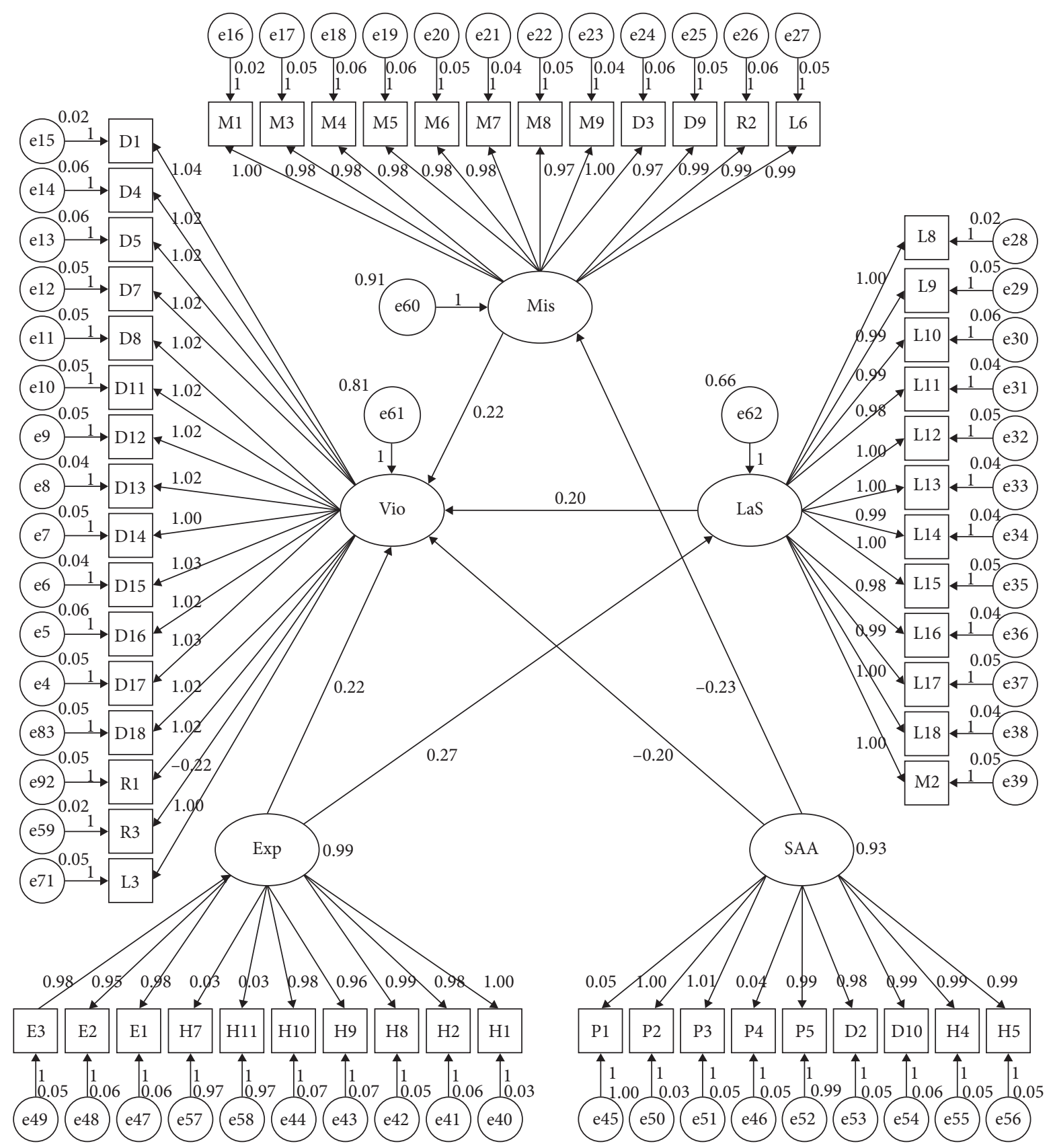

FIgURe 3: Results of the hypothetical structural model.

By comparing the goodness-of-fit values of the model before and after the modification (see Table 7), $\chi^{2} / \mathrm{DF}$ decreased from 5.697 to 2.392 , and the fitting indexes were better than before the correction. The values of GFI, CFI, NFI, and IFI all reached the standard value, which means the driving behaviour analysis model has a good fit. The structure of final driving behaviour questionnaire is shown in Table 6. The manifested variables in each category can provide reference for measuring driving behaviour, driver's psychology, driving experience, and other factors that are difficult to measure directly.
3.2. Analysis and Calculation Based on Path Coefficients. By sorting out the path values, latent variables, and observation variables in Figure 4, the evaluation indexes of driving behaviour and its influencing factors are extracted. The structure diagram is shown in Figure 5. The results are as follows:

(1) The total influencing coefficient of Exp on Vio is 0.29 (direct impact coefficient is 0.23 , and indirect impact coefficient is $0.27 * 0.21 \approx 0.06$ ). The direct influencing coefficient of Exp on LaS is 0.27 , so it can be seen that the lack of driving experience can promote 
TABLE 6: Structure of final driving behaviour questionnaire.

\begin{tabular}{|c|c|c|}
\hline Categories & Concise generalization & Items \\
\hline Lapse and slips & $\begin{array}{c}\text { Distracted driving } \\
\text { Vehicle condition control and monitoring } \\
\text { Perception of road environment } \\
\text { The choice of correct driving lane } \\
\text { Blind area monitoring }\end{array}$ & $\begin{array}{l}\text { L9, L10 } \\
\text { L11, L16, L18 } \\
\text { L12, L15 } \\
\text { L13, L14 } \\
\text { L17, L18, M2 }\end{array}$ \\
\hline Violations & $\begin{array}{c}\text { Aggressive driving behaviour } \\
\text { Emotional driving behaviour } \\
\text { Egoism behaviour }\end{array}$ & $\begin{array}{c}\text { D4, D5, D7, D8, D14, D16, D18, R1 } \\
\text { D1, D11, D12, D13, D15, D17 } \\
\text { L3 }\end{array}$ \\
\hline Mistakes & $\begin{array}{c}\text { Wrong identification of traffic signs } \\
\text { Wrong lane selection } \\
\text { Distracted driving } \\
\text { Illegal driving } \\
\text { Distance misjudgement }\end{array}$ & $\begin{array}{c}\text { M1 } \\
\text { M3, M7, M8, D3 } \\
\text { M4 } \\
\text { M5, D9, L6 } \\
\text { M6, M9, R2 }\end{array}$ \\
\hline Experience & $\begin{array}{c}\text { Vehicle condition control and monitoring } \\
\text { Vehicle peripheral monitoring } \\
\text { Driving confidence } \\
\text { Experienced cautious driving style } \\
\text { Emergency handling }\end{array}$ & $\begin{array}{c}\mathrm{H} 1, \mathrm{H} 2 \\
\mathrm{H} 8, \mathrm{H} 9, \mathrm{H} 10 \\
\text { P1 } \\
\text { P4, E3 } \\
\text { E1, E2 }\end{array}$ \\
\hline Safety awareness and attitude & $\begin{array}{c}\text { Attitude to ADAS } \\
\text { Attitude to other drivers } \\
\text { Attitude to pedestrians } \\
\text { Bad driving behaviours } \\
\text { Attitude to traffic regulations } \\
\text { Self-safety awareness } \\
\text { Safety awareness to others }\end{array}$ & $\begin{array}{l}\text { P2 } \\
\text { P3, P5 } \\
\text { D2 } \\
\text { H4, H5 } \\
\text { D10, R3 } \\
\text { H7 } \\
\text { H11 }\end{array}$ \\
\hline
\end{tabular}

TABLE 7: Comparison of the goodness-of-fit values between the hypothetical model and the modified model.

\begin{tabular}{lccc}
\hline Fit indices & Recommended value & Before revision & After revision \\
\hline$\chi^{2} / \mathrm{DF}$ & $1 \sim 3$ & 5.697 & 2.392 \\
GFI & $\geq 0.9$ & 0.706 & 0.849 \\
AGFI & $\geq 0.8$ & 0.684 & 0.838 \\
CFI & $\geq 0.9$ & 0.902 & 0.971 \\
NFI & $\geq 0.9$ & 0.884 & 0.951 \\
IFI & $\geq 0.9$ & 0.903 & 0.971 \\
TLI & $\geq 0.9$ & 0.899 & 0.970 \\
RMSEA & $\leq 0.08$ & 0.094 & 0.051 \\
\hline
\end{tabular}

TABLE 8: Path coefficients of the hypothetical structural model.

\begin{tabular}{|c|c|c|c|c|c|c|c|c|c|c|c|}
\hline Path & Estimate & C.R. & $P$ & Path & Estimate & C.R. & $P$ & Path & Estimate & C.R. & $P$ \\
\hline $\mathrm{LaS} \leftarrow \operatorname{Exp}$ & 0.27 & 7.534 & $* * *$ & $\mathrm{M} 1 \leftarrow \mathrm{Mis}$ & 1 & - & - & $\mathrm{L} 18 \leftarrow \mathrm{LaS}$ & 1 & 74.819 & **** \\
\hline $\mathrm{Mis} \leftarrow \mathrm{SAA}$ & -0.23 & -5.284 & $* * *$ & $\mathrm{M} 3 \leftarrow \mathrm{Mis}$ & 0.977 & 82.261 & $* * *$ & $\mathrm{M} 2 \leftarrow \mathrm{LaS}$ & 0.999 & 70.054 & $* * *$ \\
\hline $\mathrm{Vio} \leftarrow \mathrm{Mis}$ & 0.222 & 5.348 & $* * *$ & $\mathrm{M} 4 \leftarrow \mathrm{Mis}$ & 0.979 & 78.667 & $* * *$ & $\mathrm{H} 1 \leftarrow \operatorname{Exp}$ & 1 & - & - \\
\hline $\mathrm{Vio} \leftarrow \mathrm{LaS}$ & 0.205 & 4.202 & $* * *$ & $\mathrm{M} 5 \leftarrow \mathrm{Mis}$ & 0.978 & 79.83 & $* * *$ & $\mathrm{H} 2 \leftarrow \operatorname{Exp}$ & 0.977 & 73.308 & $* * *$ \\
\hline Vio $\leftarrow$ SAA & -0.2 & -4.735 & $* * *$ & $\mathrm{M} 6 \leftarrow \mathrm{Mis}$ & 0.983 & 82.447 & $* * *$ & $\mathrm{H} 7 \leftarrow \operatorname{Exp}$ & 0.028 & 0.639 & 0.523 \\
\hline VioŁExp & 0.221 & 5.265 & $* * *$ & M7 $\leftarrow$ Mis & 0.981 & 87.988 & $* * *$ & $\mathrm{H} 8 \leftarrow \operatorname{Exp}$ & 0.988 & 79.909 & $* * *$ \\
\hline $\mathrm{L} 3 \leftarrow \mathrm{Vio}$ & 1 & - & - & $\mathrm{M} 8 \leftarrow \mathrm{Mis}$ & 0.974 & 83.402 & $* * *$ & $\mathrm{H} 9 \leftarrow \operatorname{Exp}$ & 0.964 & 68.949 & $* * *$ \\
\hline $\mathrm{R} 1 \leftarrow \mathrm{Vio}$ & 1.023 & 73.71 & $* * *$ & $\mathrm{M} 9 \leftarrow \mathrm{Mis}$ & 1.001 & 88.661 & $* * *$ & $\mathrm{H} 10 \leftarrow \operatorname{Exp}$ & 0.984 & 72.016 & $* * *$ \\
\hline D18 $\leftarrow$ Vio & 1.021 & 72.601 & $* * *$ & $\mathrm{D} 3 \leftarrow \mathrm{Mis}$ & 0.974 & 77.81 & $* * *$ & $\mathrm{H} 11 \leftarrow \operatorname{Exp}$ & 0.029 & 0.663 & 0.507 \\
\hline $\mathrm{D} 17 \leftarrow$ Vio & 1.027 & 72.885 & $* * *$ & $\mathrm{D} 9 \leftarrow \mathrm{Mis}$ & 0.986 & 83.606 & $* * *$ & $\mathrm{E} 1 \leftarrow \operatorname{Exp}$ & 0.98 & 74.487 & $* * *$ \\
\hline D16 Vio & 1.017 & 68.226 & $* * *$ & $\mathrm{R} 2 \leftarrow \mathrm{Mis}$ & 0.986 & 80.271 & $* * *$ & $\mathrm{E} 2 \leftarrow \operatorname{Exp}$ & 0.952 & 72.162 & $* * *$ \\
\hline D15 Vio & 1.027 & 74.666 & $* * *$ & L6 $\leftarrow$ Mis & 0.985 & 85.305 & $* * *$ & $\mathrm{E} 3 \leftarrow \operatorname{Exp}$ & 0.978 & 77.372 & $* * *$ \\
\hline D14 Vio & 1.003 & 70.161 & $* * *$ & $\mathrm{~L} 8 \leftarrow \mathrm{LaS}$ & 1 & - & - & $\mathrm{P} 1 \leftarrow \mathrm{SAA}$ & 0.046 & 1.022 & 0.307 \\
\hline D13 Vio & 1.024 & 75.156 & $* * *$ & $\mathrm{~L} 9 \leftarrow \mathrm{LaS}$ & 0.986 & 69.682 & $* * *$ & $\mathrm{P} 2 \leftarrow \mathrm{SAA}$ & 1 & - & - \\
\hline
\end{tabular}


TABle 8: Continued.

\begin{tabular}{|c|c|c|c|c|c|c|c|c|c|c|c|}
\hline Path & Estimate & C.R. & $P$ & Path & Estimate & C.R. & $P$ & Path & Estimate & C.R. & $P$ \\
\hline $\mathrm{D} 12 \leftarrow \mathrm{Vio}$ & 1.015 & 72.633 & $* * *$ & $\mathrm{~L} 10 \leftarrow \mathrm{LaS}$ & 0.986 & 68.049 & $* * *$ & $\mathrm{P} 3 \leftarrow \mathrm{SAA}$ & 1.013 & 80.123 & $* * *$ \\
\hline $\mathrm{D} 11 \leftarrow \mathrm{Vio}$ & 1.018 & 72.713 & $* * *$ & $\mathrm{~L} 11 \leftarrow \mathrm{LaS}$ & 0.977 & 74.258 & $* * *$ & $\mathrm{P} 4 \leftarrow \mathrm{SAA}$ & 0.039 & 0.87 & 0.384 \\
\hline $\mathrm{R} 3 \leftarrow$ Vio & -0.224 & -5.402 & $* * *$ & $\mathrm{~L} 12 \leftarrow \mathrm{LaS}$ & 1.003 & 73.931 & $* * *$ & $\mathrm{P} 5 \leftarrow \mathrm{SAA}$ & 0.994 & 81.872 & $* * *$ \\
\hline $\mathrm{D} 8 \leftarrow \mathrm{Vio}$ & 1.021 & 71.747 & $* * *$ & $\mathrm{~L} 13 \leftarrow \mathrm{LaS}$ & 0.999 & 77.335 & $* * *$ & $\mathrm{D} 2 \leftarrow \mathrm{SAA}$ & 0.982 & 76.561 & $* * *$ \\
\hline $\mathrm{D} 7 \leftarrow \mathrm{Vio}$ & 1.016 & 73.164 & $* * *$ & $\mathrm{~L} 14 \leftarrow \mathrm{LaS}$ & 0.994 & 78.108 & $* * *$ & $\mathrm{D} 10 \leftarrow \mathrm{SAA}$ & 0.989 & 75.543 & $* * *$ \\
\hline $\mathrm{D} 5 \leftarrow \mathrm{Vio}$ & 1.018 & 68.899 & *** & $\mathrm{L} 15 \leftarrow \mathrm{LaS}$ & 1.003 & 70.004 & $* * *$ & $\mathrm{H} 4 \leftarrow \mathrm{SAA}$ & 0.995 & 81.042 & $* * *$ \\
\hline $\mathrm{D} 4 \leftarrow \mathrm{Vio}$ & 1.02 & 70.28 & $* * *$ & $\mathrm{~L} 16 \leftarrow \mathrm{LaS}$ & 0.984 & 74.61 & $* * *$ & $\mathrm{H} 5 \leftarrow \mathrm{SAA}$ & 0.994 & 79.244 & $* * *$ \\
\hline $\mathrm{D} 1 \leftarrow \mathrm{V}$ io & 1.041 & 87.044 & $* * *$ & $\mathrm{~L} 17 \leftarrow \mathrm{LaS}$ & 0.994 & 70.609 & $* * *$ & & & & \\
\hline
\end{tabular}

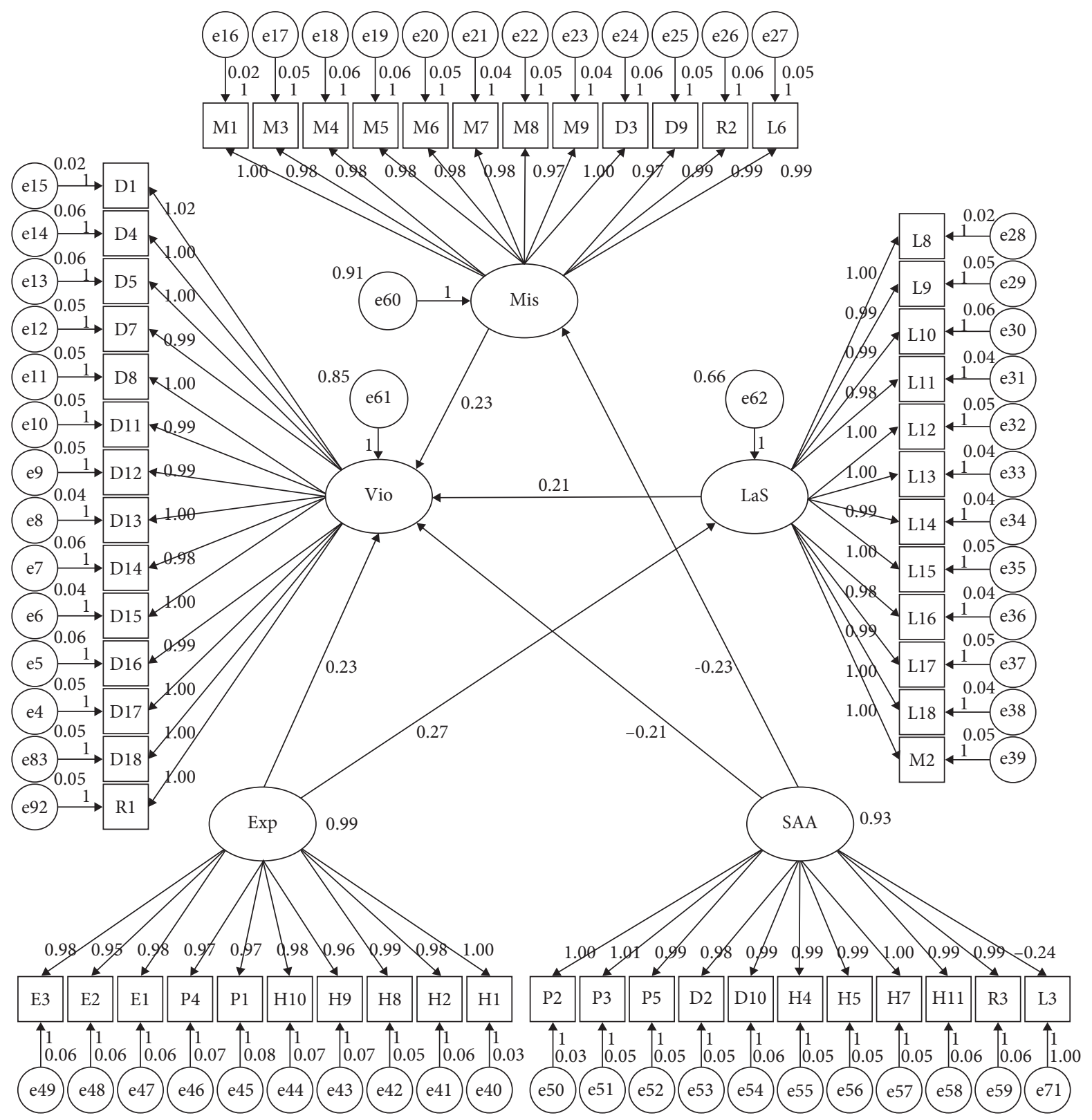

FIgURE 4: Driving behaviour analysis model. 


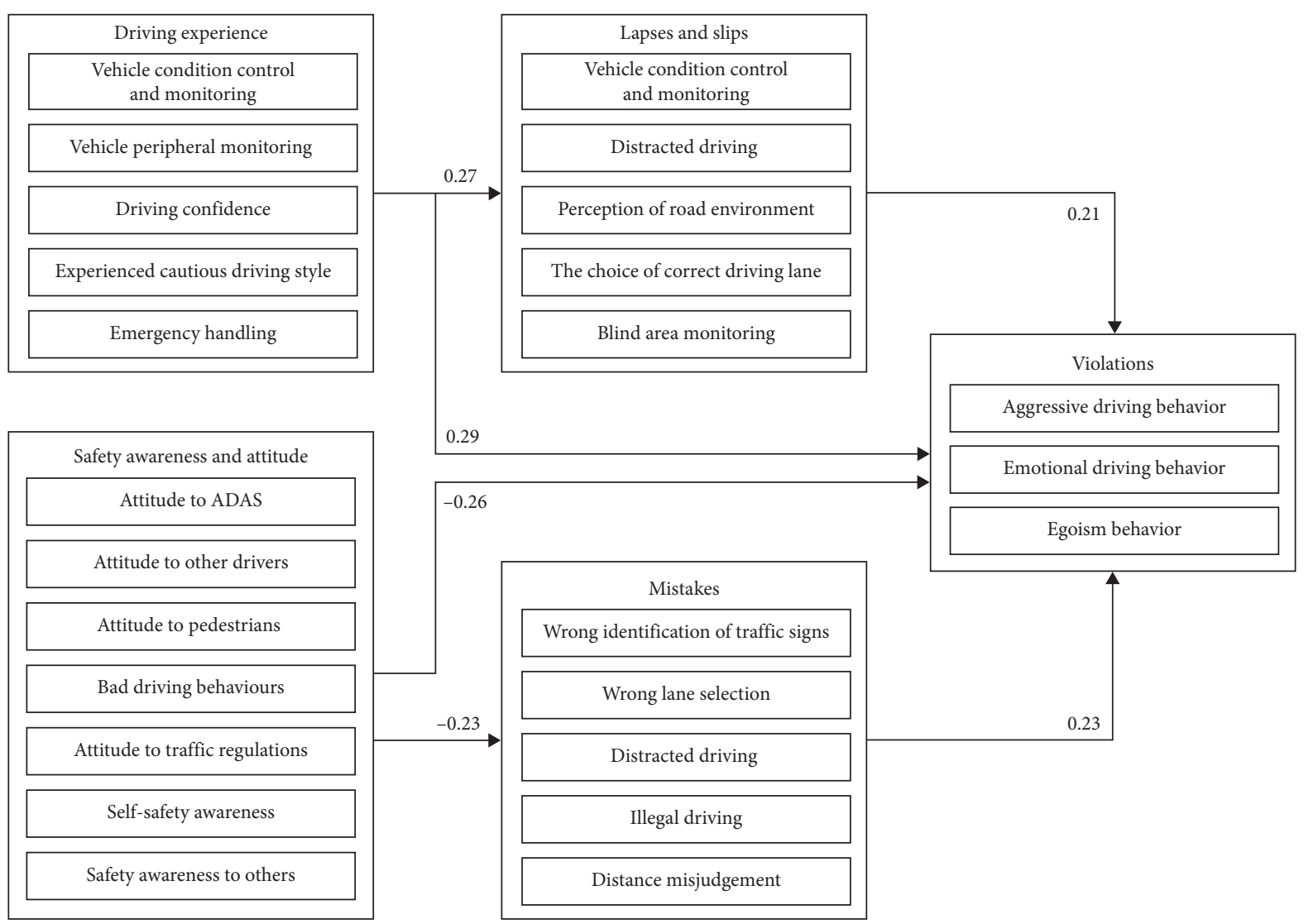

FIgURE 5: Schematic diagram of driving behaviour and its influencing factors.

the violation behaviours and the lapses and slips behaviours.

(2) The total influencing coefficient of SAA on Vio is -0.26 (direct impact coefficient is -0.21 , and indirect impact coefficient is $-0.23 * 0.23 \approx 0.05$ ). The direct influencing coefficient of SAA on Mis is -0.23 . It is shown that good safety attitude and awareness can inhibit the violation behaviours and the mistake behaviours, especially the violation behaviours.

(3) In addition to driving experience, safety attitude, and awareness, violations are also influenced by mistakes, lapses, and slips. The influencing coefficients of Mis and $\mathrm{LaS}$ on Vio are 0.23 and 0.21 , respectively. It shows that there is a chance that error driving behaviour will be transformed into violation driving behaviours.

\section{Discussion}

4.1. Summaries and Conclusions. Latent factors such as driving experience, psychology, and attitude are important elements affecting driving behaviour; however, it is difficult to quantify their influencing mechanism by means of direct instruments. The self-report survey method is a commonly used and effective method to solve this kind of problems. In this paper, based on the results of previous related research studies, we developed a refined version of a 59-item Chinese driving behaviour questionnaire. The results confirmed that the structure of the questionnaire has good construct validity and that it is a useful scale to measure the self-reported driving behaviours in China. Moreover, after the deconstruction of driving behaviour and its influencing factors by $\mathrm{TPB}$, the hypothesis structural equation model was built, tested, and improved into a well-organized version. Taking the path direction and the path value as the direction and degree of action among latent variables, combining with the actual item contents, the influencing mechanism among driving behaviours and its influencing factors was analysed. Finally, we reached the following conclusions:

(1) The influence coefficients of Exp on Vio and LaS are 0.29 and 0.27 , respectively, indicating that driving experience has an impact on violations, lapses, and slips. Combining the contents of the items, with the goal of reducing violations and lapses and slips, it should be improved from the following aspects: vehicle peripheral monitoring ( $\mathrm{H} 8, \mathrm{H} 9$, and $\mathrm{H} 10)$, vehicle condition control and monitoring (H1 and $\mathrm{H} 2$ ), experienced cautious driving style (P4 and E3), emergency handling (E1 and E2), and driving confidence (P1).

(2) The influencing coefficients of SAA on Vio and Mis are -0.26 and -0.23 , respectively, indicating that good safety awareness and attitude can inhibit violations and mistakes. Combined with the actual content of manifested variables, it is necessary to 
improve and correct the driver's psychology, attitude, and awareness to reduce the violational driving behaviours and bad driving behaviours. And it should be improved from the following aspects: attitude to other drivers (P3 and $\mathrm{P} 5$ ) and pedestrians (D2), attitude to traffic regulations (D10 and R3), bad driving behaviours ( $\mathrm{H} 4$ and $\mathrm{H} 5$ ), self-safety awareness (H7), attitude to ADAS (P2), and safety awareness to others (H11).

(3) LaS and Mis, respectively, are intermediary effect behaviours between Exp and Vio, SAA, and Vio. Which means although LaS and Mis are the actual behaviours behaved by drivers, they are not exactly the terminal from the plan to the behaviour; in some cases, they will be converted to Vio. Based on (1) and (2), the prime aim of improving road traffic safety is to reduce Vio; the main measures of which are to educate and correct the drivers' Exp and SAA. Furthermore, drivers' LaS and Mis are buffering and transition processes, which should be corrected timely and prevented from continuing to develop into Vio.

To sum up, the Chinese driving behaviour questionnaire designed in this paper can be used to study and measure the driving behaviour, driving psychology and driving experience. The results of the study also have certain practical application and theoretical support reference value for improving road traffic safety, reducing the threat of drivers to road users, and training and educating drivers.

4.2. Limitations and Prospects. This paper aims to improve road traffic safety from the perspective of improving and reducing bad driving behaviours and can also provide reference for the training program of driving schools. The advantages of the current study are based on the demographic characteristics of Chinese drivers, and this makes the conclusions close to the actual situation as much as possible. However, due to not all drivers know enough about themselves or are unwilling to confess their real situation, for other reasons, the questionnaire may be affected by the driver's subjective errors. We believe that using the present analysis results and real vehicle driving tests to verify each other could better solve this problem. Before coming to fully autonomous driving stage, it is necessary to explore better ways to educate and restrain drivers scientifically and improve traffic safety.

\section{Data Availability}

The data used to support the result of this study are available from the corresponding author upon request.

\section{Conflicts of Interest}

The authors declare that there are no conflicts of interest regarding the publication of this paper.

\section{Acknowledgments}

This work was supported by the National Natural Science Foundation of China (52072333), Natural Science Foundation of Hebei Province (E2020203092), Hebei Provincial Key Research Projects (no. 20310801D), National Natural Science Foundation of China (no. U19A2069), National Key Research and Development Program of China (2018YFB1600501), and the First Batch of 2020 MOE Industry-University Collaborative Education Program (program no.202001SJ05, Kingfar-CES "Human Factors and Ergonomics Program").

\section{Supplementary Materials}

Supplementary Materials (Chinese driving behaviour questionnaire) are provided as an attached document along with the article. (Supplementary Materials)

\section{References}

[1] China Road Traffic Accidents Statistics, Traffic Administration Bureau of the Ministry of Public Security of PRC, China Road Traffic Accidents Statistics, Beijing, China, 2013.

[2] L. Melton, B. Guo, Y. Jiang, F. Wang, X. Xie, and M. Gao, "Study on the impact degrees of several driving behaviors when driving while performing secondary tasks," IEEE Access, vol. 6, pp. 65772-65782, 2018.

[3] T. L. Milfont and R. Fischer, "Testing measurement invariance across groups: applications in cross-cultural research," International Journal of Psychological Research, vol. 3, no. 1, pp. 111-130, 2010.

[4] D. R. Mayhew, H. M. Simpson, and A. Pak, "Changes in collision rates among novice drivers during the first months of driving," Accident Analysis \& Prevention, vol. 35, no. 5, pp. 683-691, 2003.

[5] J. Kroenung and A. Eckhardt, "The attitude cube-a threedimensional model of situational factors in is adoption and their impact on the attitude-behavior relationship," Information \& Management, vol. 52, no. 6, pp. 611-627, 2015.

[6] K. T. Hua and Z. J. Cheng, "Application and analytical strategies of structural equation modelling," Exploration of Psychology, vol. 19, no. 69, pp. 54-59, 1999.

[7] J. Reason, A. Manstead, S. Stradling et al., "Errors and violations on the roads: a real distinction?" Ergonomics, vol. 33, no. 10-11, pp. 1315-1332, 1990.

[8] L. M. Martinussen, L. Hakamies-Blomqvist, M. Møller, T. Özkan, and T. Lajunen, "Age, gender, mileage and the DBQ: the validity of the driver behavior questionnaire in different driver groups," Accident Analysis \& Prevention, vol. 52, pp. 228-236, 2013.

[9] D. Lauro, R. Zhang, and X. Qu, "The role of personality traits and driving experience in self-reported risky driving behaviors and accident risk among Chinese drivers," Accident Analysis \& Prevention, vol. 99, pp. 228-235, 2017.

[10] B. Guo, L. Jin, D. Sun, J. Shi, and F. Wang, "Establishment of the characteristic evaluation index system of secondary task driving and analyzing its importance," Transportation Research Part F: Traffic Psychology and Behaviour, vol. 64, pp. 308-317, 2019.

[11] T. Özkan, T. Lajunen, J. E. Chliaoutakis, D. Parker, and H. Summala, "Cross-cultural differences in driving 
behaviours: a comparison of six countries," Transportation Research Part F: Traffic Psychology and Behaviour, vol. 9, no. 3, pp. 227-242, 2006.

[12] A. E. Curry, K. B. Metzger, A. F. Williams, and B. C. Tefft, "Comparison of older and younger novice driver crash rates: informing the need for extended graduated driver licensing restrictions," Accident Analysis \& Prevention, vol. 108, pp. 66-73, 2017.

[13] M. Van Gelderen, M. Brand, M. Van Praag, W. Bodewes, E. Poutsma, and A. Van Gils, "Explaining entrepreneurial intentions by means of the theory of planned behaviour," Career Development International, vol. 13, no. 6, pp. 538-559, 2008.

[14] Y.-H. Huang, W. Zhang, M. Roetting, and D. Melton, "Experiences from dual-country drivers: driving safely in China and the us," Safety Science, vol. 44, no. 9, pp. 785-795, 2006.

[15] M. Fishbein and I. Ajzen, "Belief, attitude, intention, and behavior: an introduction to theory and research," Contemporary Sociology, vol. 6, no. 2, 1977.

[16] M. Tenenhaus, V. E. Vinzi, Y.-M. Chatelin, and C. Lauro, "Pls path modeling," Computational Statistics \& Data Analysis, vol. 48, no. 1, pp. 159-205, 2005.

[17] E. Yadegaridehkordi, M. H. Nizam Bin Md Nasir, N. Fazmidar Binti Mohd Noor, L. Shuib, and N. Badie, "Predicting the adoption of cloud-based technology using fuzzy analytic hierarchy process and structural equation modelling approaches," Applied Soft Computing, vol. 66, pp. 77-89, 2018.

[18] C. Siebe, "Distracted driving and risk of road crashes among novice and experienced drivers," The Journal of Emergency Medicine, vol. 46, no. 4, pp. 54-59, 2014.

[19] A. Dinis, A. Do Paço, J. Ferreira, M. Raposo, and R. Gouveia Rodrigues, "Psychological characteristics and entrepreneurial intentions among secondary students," Education + Training, vol. 55, no. 8/9, pp. 763-780, 2013.

[20] C. Schlaegel and M. Koenig, "Determinants of entrepreneurial intent: a meta-analytic test and integration of competing models," Entrepreneurship Theory and Practice, vol. 38, no. 2, pp. 291-332, 2014.

[21] WHO, Global Status Report on Road Safety 2015, World Health Organization, Geneva, Switzerland, 2015.

[22] W. Qu, Y. Ge, C. Jiang, F. Du, and K. Zhang, "The Dula dangerous driving index in China: an investigation of reliability and validity," Accident Analysis \& Prevention, vol. 64, pp. 62-68, 2014.

[23] P. Stahl, B. Donmez, and G. A. Jamieson, "Eye glances towards conflict-relevant cues: the roles of anticipatory competence and driver experience," Accident Analysis \& Prevention, vol. 132, pp. P105-P255, 2019.

[24] J. Shi, Y. Bai, X. Ying, and P. Atchley, "Aberrant driving behaviors: a study of drivers in beijing," Accident Analysis \& Prevention, vol. 42, no. 4, pp. 1031-1040, 2010.

[25] J. J. M. Ferreira, M. L. Raposo, R. Gouveia Rodrigues, A. Dinis, and A. Do Paço, "A model of entrepreneurial intention," Journal of Small Business and Enterprise Development, vol. 19, no. 3, pp. 424-440, 2012.

[26] Y. Gürol and N. Atsan, "Entrepreneurial characteristics amongst university students," Education + Training, vol. 48, no. 1, pp. 25-38, 2006.

[27] P.-A. Rimmö, "Aberrant driving behaviour: homogeneity of a four-factor structure in samples differing in age and gender," Ergonomics, vol. 45, no. 8, pp. 569-582, 2002.

[28] D. Chliaoutakis, J. T. Reason, A. S. R. Manstead, and S. G. Stradling, "Driving errors, driving violations and accident involvement," Ergonomics, vol. 38, no. 5, pp. 1036-1048, 1995.

[29] D. P. Upahita, Y. D. Wong, and K. M. Lum, "Effect of driving experience and driving inactivity on young driver"s hazard mitigation skills," Transportation Research Part F: Traffic Psychology and Behaviour, vol. 59, pp. 286-297, 2018.

[30] A. Bener, T. Özkan, and T. Lajunen, "The driver behaviour questionnaire in Arab gulf countries: Qatar and United Arab Emirates," Accident Analysis \& Prevention, vol. 40, no. 4, pp. 1411-1417, 2008.

[31] B. González-Iglesias, J. A. Gómez-Fraguela, and M. Á. Luengo-Martín, "Driving anger and traffic violations: gender differences," Transportation Research Part F: Traffic Psychology and Behaviour, vol. 15, no. 4, pp. 404-412, 2012.

[32] K. Stradling, A. Raineri, V. Beanland, J. Bell, and M. Borzycki, "Expert drivers are better than non-expert drivers at rejecting unimportant information in static driving scenes," Transportation Research Part F: Traffic Psychology and Behaviour, vol. 59, no. A, pp. 389-400, 2018.

[33] M. Naushad, "A study on the antecedents of entrepreneurial intentions among Saudi students," Entrepreneurship and Sustainability Issues, vol. 5, no. 3, pp. 600-617, 2018.

[34] B. Scott Parker, T. De Regt, C. Jones, and J. Caldwell, "The situation awareness of young drivers, middle-aged drivers, and older drivers: same but different?" Case Studies on Transport Policy, vol. 8, no. 1, pp. 206-214, 2018.

[35] X. Wang and X. Xu, "Assessing the relationship between self-reported driving behaviors and driver risk using a naturalistic driving study," Accident Analysis \& Prevention, vol. 128, pp. 8-16, 2019.

[36] A. Rauch and M. Frese, "Let"s put the person back into entrepreneurship research: a meta-analysis on the relationship between business owners" personality traits, business creation, and success," European Journal of Work and Organizational Psychology, vol. 16, no. 4, pp. 353-385, 2007.

[37] B. G. Tabachnick and L. S. Fidell, "Using multivariate statistics," Journal of Clinical Psychopharmacology, vol. 2, no. 6, 2007.

[38] L. P. Waddell and K. K. K. Wiener, "What's driving illegal mobile phone use? Psychosocial influences on drivers' intentions to use hand-held mobile phones," Transportation Research Part F: Traffic Psychology and Behaviour, vol. 22, pp. 1-11, 2014.

[39] W. Qu, Q. Zhang, W. Zhao, K. Zhang, and Y. Ge, "Validation of the driver stress inventory in China: relationship with dangerous driving behaviors," Accident Analysis \& Prevention, vol. 87, pp. 50-58, 2016.

[40] C.-Q. Xie and D. Parker, "A social psychological approach to driving violations in two Chinese cities," Transportation Research Part F: Traffic Psychology and Behaviour, vol. 5, no. 4, pp. 293-308, 2002.

[41] W. Du, W. Zhang, and Y. Ge, "The moderating effect of delay discounting between sensation seeking and risky driving behavior," Safety Science, vol. 123, Article ID 104558, 2020.

[42] W. Minglong, Structural Equation Model: Operation and Application of AMOS (2nd edtion), Chongqing university press, Chongqing, China, 2019.

[43] D. Norman, "Position paper on human error," NATO Advanced Research Workshop on Human Error, Beilagio, Italy, 1983.

[44] I. Ajzen and M. Fishbein, "Attitudes and the attitude-behavior relation: reasoned and automatic processes," European Review of Social Psychology, vol. 11, no. 1, pp. 1-33, 2000. 
[45] G. Pnina, P. E. Johnathon, C. Zhu et al., "Crash risk and risky driving behaviour among adolescents during learner and independent driving periods," Journal of Adolescent Health, vol. 63 , no. 5, pp. 568-574, 2018.

[46] L. Chandrasekaran, A. Crookes, and T. C. Lansdown, "Driver situation awareness-investigating the effect of passenger experience," Transportation Research Part F: Traffic Psychology and Behaviour, vol. 61, pp. 152-162, 2019.

[47] S. Nasip, S. R. Amirul, S. L. Sondoh Jr., and G. H. Tanakinjal, "Psychological characteristics and entrepreneurial intention," Education + Training, vol. 59, no. 7/8, p. 825, 2017.

[48] E. Gulian, G. Matthews, A. I. Glendon, D. R. Davies, and L. M. Debney, "Dimensions of driver stress," Ergonomics, vol. 32, no. 6, pp. 585-602, 1989.

[49] R. O. Mueller and O. Ralph, "Structural equation modeling: back to basics," Structural Equation Modeling: A Multidisciplinary Journal, vol. 4, no. 4, pp. 353-369, 1997.

[50] S. F. Niu, Y. J. Liu, L. Wang, and H. Q. Li, "Effects of different intervention methods on novice drivers' speeding," Sustainability, vol. 11, 2019.

[51] C. S. Dula and M. E. Ballard, "Development and evaluation of a measure of dangerous, aggressive, negative emotional, and risky Driving1," Journal of Applied Social Psychology, vol. 33, no. 2, pp. 263-282, 2003.

[52] A. M. Przepiorka, A. P. Błachnio, and M. J. M. Sullman, "Factors influencing intentions to text while driving among Polish drivers," Transportation Research Part F: Traffic Psychology and Behaviour, vol. 55, pp. 306-313, 2018.

[53] S. Matus, L. Sramkova, and R. Risser, "The manchester driver behaviour questionnaire: self-reports of aberrant behaviour among Czech drivers," European Transport Research Review, vol. 6, no. 4, pp. 493-502, 2014.

[54] I. Ajzen, "The theory of planned behavior," Organizational Behavior and Human Decision Processes, vol. 50, no. 2, pp. 179-211, 1991.

[55] R. Summala, "A technique for the measurement of attitudes," Archieves of Psychology, vol. 22, pp. 1-55, 1932.

[56] S. P. Walsh, K. M. White, M. K. Hyde, and B. Watson, "Dialling and driving: factors influencing intentions to use a mobile phone while driving," Accident Analysis \& Prevention, vol. 40, no. 6, pp. 1893-1900, 2008.

[57] J. Mesken, T. Lajunen, and H. Summala, "Interpersonal violations, speeding violations and their relation to accident involvement in Finland," Ergonomics, vol. 45, no. 7, pp. 469-483, 2002.

[58] S. T. D. Cordazzo, C. T. Scialfa, and R. J. Ross, "Modernization of the driver behaviour questionnaire," Accident Analysis \& Prevention, vol. 87, pp. 83-91, 2016.

[59] G. Sta, "Global status report on road safety," Injury Prevention, vol. 15, no. 4, p. 286, 2015.

[60] E. E. Rigdon and E. Edward, "A necessary and sufficient identification rule for structural models estimated in practice," Multivariate Behavioral Research, vol. 30, no. 3, pp. 359-383, 1995.

[61] P.-A. Rimmö and L. Åberg, "On the distinction between violations and errors: sensation seeking associations," Transportation Research Part F: Traffic Psychology and Behaviour, vol. 2, no. 3, pp. 151-166, 1999.

[62] T. Lajunen, D. Parker, and H. Summala, "The manchester driver behaviour questionnaire: a cross-cultural study," $A c$ cident Analysis \& Prevention, vol. 36, no. 2, pp. 231-238, 2004. 